\title{
Impact of maternal respiratory infections on low birth weight - a community based longitudinal study in an urban setting in Pakistan
}

Asad Ali ${ }^{1 *}$ (D, Umber Zaman', Sadia Mahmud', Gul-e-Shehwar Zahid ${ }^{1}$, Momin Kazi', William A. Petri², Zulfiqar Bhutta ${ }^{1}$, Anita Zaidi ${ }^{1}$ and Molly A. Hughes ${ }^{2}$

\begin{abstract}
Background: The health of mothers and their newborns is intricately related. The weight of the infant at birth is a powerful predictor of infant growth and survival, and is considered to be partly dependent on maternal health and nutrition during pregnancy. We conducted a longitudinal study in an urban community within Karachi to determine maternal predictors of newborn birth weight.

Methods: Four hundred pregnant women were enrolled in the study during the period 2011-2013. Data related to symptoms of acute respiratory illness (fever, cough, difficulty breathing, runny nose, sore throat, headache, chills, and myalgia/lethargy) in the pregnant women were collected weekly until delivery. Birth weight of the newborn was recorded within 14 days of delivery and the weight of $<2.5 \mathrm{~kg}$ was classified as low birth weight (LBW).

Results: A total of 9,853 symptom episodes were recorded of fever, cough, difficulty breathing, runny nose, sore throat, headache, chills, myalgias/lethargy in the enrolled pregnant women during the study. Out of 243 pregnant women whose newborns were weighed within 14 days of birth, LBW proportion was $21 \%(n=53)$. On multivariate analysis, independent significant risk factors noted for delivering LBW babies were early pregnancy weight of $<57$. $5 \mathrm{~kg}$ [odds ratio adjusted $\left.\left(\mathrm{OR}_{\mathrm{adj}}\right)=5.1,95 \% \mathrm{Cl}:(1.3,19.9)\right]$ and gestational age $\left[\mathrm{OR}_{\mathrm{adj}}=0.3,95 \% \mathrm{Cl}(0.2,0.7)\right.$ for every one week increase in gestational age]. Among mothers with high socioeconomic status (SES), every 50-unit increase in the number of episodes of respiratory illness $/ 100$ weeks of pregnancy had a trend of association with an increased risk of delivering LBW infants $\left[O \mathrm{R}_{\mathrm{adj}}=1.7,95 \% \mathrm{Cl}\right.$ : $\left.(1.0,3.1)\right]$. However, among mothers belonging to low $\mathrm{SES}$, there was no association of the number of episodes of maternal respiratory illness during pregnancy with infants having LBW $\left[O R_{a d j}=0.9,95 \% \mathrm{Cl}:(0.5,3.5)\right]$.

Conclusions: While overall respiratory illnesses during pregnancy did not impact newborn weight in our study, we found this trend in the sub-group of mothers belonging to the higher SES. Whether this is because in mothers belonging to lower SES, the effects of respiratory illnesses were overshadowed by other risk factors associated with poverty need to be further studied.
\end{abstract}

Keywords: Pregnancy, Respiratory illness, ARI, Newborn weight, Longitudinal observational study

\footnotetext{
* Correspondence: Asad.ali@aku.edu

${ }^{1}$ Department of Pediatrics and Child Health, The Aga Khan University, Karachi 74800, Pakistan
}

Full list of author information is available at the end of the article 


\section{Background}

An estimated 358,000 women die annually due to complications that develop during pregnancy and childbirth [1]. For every woman who dies, at least 20 more suffer from pregnancy related injuries, infections, diseases and disabilities, often with lifelong consequences [2]. The health of mothers and newborns is intricately related, so improving outcomes in either requires effective nutrition, infection control measures, and antenatal care.

Pregnant women are vulnerable to viral respiratory infections $[3,4]$ and are considered to be at high risk for influenza [5] and its complications [6-8]. Preventing influenza in mothers leads to increase in birth weights [9] and reduced infections in newborns $[10,11]$. While the impact of influenza during pregnancy on newborns is now better understood $[7,8,12,13]$, the importance of other respiratory infections has not been studied. In order to improve maternal and neonatal outcomes and to develop appropriate preventive and treatment strategies, the association between common maternal illness and newborn's health needs to be studied. Therefore, we conducted this study to identify the association between maternal respiratory illnesses and infant birth weight in an urban slum of Pakistan.

\section{Methods}

This study was conducted under approval by institutional review boards at the Aga Khan University, Karachi, Pakistan and University of Virginia, Charlottesville, Virginia, USA. Informed consent was obtained from the adult participants and by a parent's informed consent for newborns. The study was conducted during the period from July 2011 to June 2013 in Bilal Colony, which is an urban settlement within Karachi, Pakistan. The total population of Bilal Colony is 76,361. The total number of women of reproductive age (15-49 years) is 17,351 , and the number of children less than five years old is 11,023 (2010 baseline survey). This site has an ongoing demographic surveillance system (DSS) where baseline census has been performed. Information on the following are conducted routinely every three months: number of events of pregnancy, births, and deaths; migration in or out of the community; and number of married women.

A longitudinal, observational cohort study was conducted in which women in their first trimester or early second trimester of pregnancy were randomly selected from the list of pregnant women of Bilal Colony (DSS). Informed consent was obtained, and participants were enrolled and subsequently followed once weekly for symptoms of respiratory or febrile illness until delivery. The study was designed to document the timing and sequence of respiratory symptom episodes and to identify any association of these symptoms in the pregnant women to the newborn's weight.
The sample size calculated for pregnant women was approximately 300 based on an assumption of $5 \%$ influenza rates in adults, with a margin of error of $5.62 \%$ and $95 \%$ confidence level. The total number of pregnant women enrolled in the study was 400 in order to account for attrition due to noncompliance with the study protocol, withdrawal from the study, and movement of participants out of the area.

Illness in the pregnant women was detected either by once weekly household visits by trained study health care workers, or through the pregnant women contacting project personnel at the field office, an easy walk from all of the homes enrolled in the study. On each weekly visit, the participants were questioned regarding symptoms of respiratory illness, diarrhea, vomiting and fever in the last seven days. A brief standard questionnaire was administered either at home or in the clinic if a pregnant woman had developed signs or symptoms of acute respiratory illness (ARI). The clinic in the field office is staffed with an obstetrics/gynecology medical officer who provided free care to the study participants and their immediate family, with health care available at the government hospital when the clinic was closed. The field teams encouraged the study participants to visit the clinic for any symptom. Appropriate and standard health care was provided to all the study participants according to the local standards.

\section{Statistical methods}

Descriptive statistics and inferential data analyses were conducted using SPSS 17.0 [14]. Mean and standard deviation were computed for quantitative and proportions for categorical variables.

The outcome variable, weight of the newborns, was measured within 0-14 days of birth. The mean age of infants when the birth weight was recorded was 4.9 days (SD 3.7 days). The weight of the mothers was measured at the mean gestational age of 12.7 weeks (SD 4.4 Weeks). The signs and symptoms of maternal respiratory illness during pregnancy were recorded as the number of episodes of fever, cough, difficulty breathing, runny nose, sore throat, headache, chills, and myalgias/lethargy throughout the follow-up period. The number of episodes of each of these signs and symptoms per 100 weeks of pregnancy were computed. A principle component analysis [15] of the eight respiratory illness signs and symptoms episodes per 100 weeks of pregnancy was conducted. The first principle component explains $38 \%$, and the second $17 \%$, of the total variance of the 8 items. The values of eigenvector of the first principle component indicate that all 8 items contribute to the total score for the first component, and no item dominates. Scores based on the first component correlate highly with the total number of episodes of signs and symptoms of respiratory illness per 100 weeks 
of pregnancy $(r=0.989)$. Hence, in order to quantify maternal respiratory illness during pregnancy, we used the total number of episodes of signs and symptoms of respiratory illness per 100 weeks of pregnancy.

Multivariable logistic regression analysis was conducted to identify factors associated independently with infant LBW; LBW was categorized as $<2.5 \mathrm{~kg}$. We conducted univariable logistic regression analysis for each of the socio-demographic and clinical characteristics of the pregnant mothers compared to delivery of LBW newborns. The criteria for selecting a variable for inclusion in the multivariable model was a (likelihood ratio test) $p$-value $<0.25$ from the univariable logistic regression analysis, and variables considered to be of biological importance. In the multivariable model, scale of all continuous predictor variables was examined using the quartile analysis method. Confounding effects of variables, with insignificant Wald p-values in the multivariable model on other variables, were assessed. Biologically meaningful interactions between variables in the model were assessed for statistical significance [16].

\section{Results}

Among the 400 women initially enrolled in the study, 157 were lost to follow-up by the time of delivery, mainly due to migration before or at the time of delivery. Out of the 243 infant deliveries, 21\% $(n=51)$ were LBW newborns. At the first clinic visit of the pregnant mother, the average age and average weight of the pregnant women in the study were 24.1 years and $56.1 \mathrm{~kg}$, respectively. Thirty two percent $(n=76)$ of the mothers had primary education or above, and only $26 \%(n=62)$ of the women had antenatal visits during their pregnancy. The mean age of mothers (23 years) was found to be lower in those who had newborns with lower birth weights compared to those who had newborns with birth weight $>2.5 \mathrm{~kg}$ (24.4 years). In our study cohort, the major source of drinking water was piped water in the households, which was more frequently available for pregnant women who had newborns weighing $>2.5 \mathrm{~kg}$ (36.9\%) compared to pregnant women who had LBW newborns (31.4\%). Use of water bought from drums was a more frequent practice of mothers of infants with LBW (37.2\%) compared to mothers of infants with birth weight $>2.5 \mathrm{~kg}(29.7 \%)$ (Table 1).

The results of univariate logistic regression analysis are reported in Table 2. The socio-demographic characteristics of pregnant women associated with infants with low birth weight included age, gravidity, and maternal weight at first visit. A higher total score for household assets correlated with a decreased risk of delivering LBW infant. Increased gestational age was associated with a significantly reduced risk of LBW (Table 2).

Complete data sets were available for 222 women for the multivariable model. There were a total of $9,853 \mathrm{symp-}$ tom episodes recorded of fever, cough, difficulty breathing, runny nose, sore throat, headache, chills, and myalgias/ lethargy of the pregnant women during their pregnancy. In the multivariable model, factors associated with LBW were lower weight of mother at first visit, higher gravidity, shorter gestational age of newborn, higher household socio-economic status, higher number of episodes of respiratory symptoms, and higher number of fever episodes. There were two interactions in the model; one between number of episodes of respiratory symptoms and SES, and another between gravidity and number of fever episodes. After adjusting for other variables in the model infants born to mothers with weight at first visit of $<57.5 \mathrm{~kg}$ were at 5-fold risk for LBW relative to mothers with weight $\geq$ $57.5 \mathrm{~kg}$ [ORadj $=5.1,95 \% \mathrm{CI}:(1.3,19.9)]$ (Table 3).

There is evidence for an interaction between number of episodes of maternal respiratory illness symptoms/ 100 weeks of pregnancy with the pregnant mother's SES. This implies that the effect of maternal respiratory illness symptom episodes during pregnancy on infant LBW outcome depends on a mother's SES. Among mothers with high SES, for every 50-unit increase in number of episodes of respiratory illness/100 weeks of pregnancy the risk of infant's LBW increased 1.7 times $\left[\mathrm{OR}_{\mathrm{adj}}=1.7,95 \% \mathrm{CI}\right.$ : $\left.(1.0,3.1)\right]$. However, among pregnant mothers belonging to lower SES there is no significant association of number of episodes of maternal respiratory illness during pregnancy with a subsequent newborn with LBW $\left[\mathrm{OR}_{\mathrm{adj}}=0.9,95 \% \mathrm{CI}:(0.5,3.5)\right]$ (Table 3). In addition, there was an interaction between number of fever episodes/100 weeks of pregnancy and gravidity in the multivariable model. If gravidity is 3 or less, there is no significant impact of maternal fever episodes during pregnancy on whether a newborn is LBW or not. However, with increasing gravidity there is a significant and progressively increasing adverse association of the number of maternal fever episodes during pregnancy with a newborn having LBW. Infants born to mothers who had $\geq 11$ fever episodes/100 weeks of pregnancy had more than 3 times higher risk when gravidity was $5\left[\mathrm{OR}_{\mathrm{adj}}=3.4,95 \% \mathrm{CI}:(1.1,10.5)\right]$ and 9 times higher risk when gravidity was $7\left[\mathrm{OR}_{\mathrm{adj}}=9.0,95 \% \mathrm{CI}:(1.4,57.6)\right]$ relative to infants born to mothers who had $<11$ fever episodes/100 weeks of pregnancy (Table 3).

\section{Discussion}

We found that low maternal body weight during early pregnancy and gestational age of a newborn are significant risk factors for infant LBW in our study. In the population of women with a high incidence of respiratory infections, we found that an effect of the number of episodes of maternal respiratory illness/100 weeks of pregnancy on infant LBW may depend on the pregnant mother's SES, with the impact of maternal respiratory illnesses on infant birth weight being greater on women 
Table 1 Descriptive Analysis of the characteristics of pregnant women with low birth weight infants compared to those with normal birth weight infants

\begin{tabular}{|c|c|c|c|}
\hline \multirow[t]{2}{*}{ Pregnant women characteristics } & \multirow{2}{*}{$\begin{array}{l}\text { Sample } \\
\text { size }(n)\end{array}$} & \multicolumn{2}{|l|}{ Birth weight } \\
\hline & & $\begin{array}{l}<2.5 \mathrm{~kg} \\
(\mathrm{n}=51)\end{array}$ & $\begin{array}{l}>=2.5 \mathrm{~kg} \\
(n=192)\end{array}$ \\
\hline $\begin{array}{l}\text { Age of pregnant women } \\
\text { Mean(SD); years }\end{array}$ & 243 & $23.0(3.8)$ & $24.4(4.5)$ \\
\hline \multicolumn{4}{|l|}{$\begin{array}{l}\text { Pregnant women's education; } \\
\mathrm{n}(\%)\end{array}$} \\
\hline No formal schooling & 237 & $35(68.6)$ & $126(65.6)$ \\
\hline Below $10^{\text {th }}$ grade & & $8(15.7)$ & $38(19.8)$ \\
\hline $10^{\text {th }}$ grade and above & & $6(11.8)$ & $24(12.5)$ \\
\hline $\begin{array}{l}\text { Weight at first visit of } \\
\text { pregnant women } \\
\text { mean(SD); kg }\end{array}$ & 243 & $49.0(9.0)$ & $53.6(11.7)$ \\
\hline $\begin{array}{l}\text { Height of pregnant } \\
\text { women mean(SD); } \mathrm{cm}\end{array}$ & 243 & $153.1(4.5)$ & $152.6(11.5)$ \\
\hline Gravidity, Median (IQR) & 240 & $3(2)$ & $3(3)$ \\
\hline \multicolumn{4}{|l|}{ Household characteristics } \\
\hline $\begin{array}{l}\text { No of people living in } \\
\text { household, Mean(SD) }\end{array}$ & 243 & $8.9(5.5)$ & $8.7(5.5)$ \\
\hline $\begin{array}{l}\text { No of rooms in the } \\
\text { household Mean(SD) }\end{array}$ & 242 & $2.5(1.5)$ & $2.4(1.4)$ \\
\hline $\begin{array}{l}\text { Total score of household } \\
\text { assets, Mean(SD) }\end{array}$ & 243 & $154.3(141.9)$ & $201.1(179.0)$ \\
\hline $\begin{array}{l}\text { Main source of drinking } \\
\text { water; } \mathrm{n}(\%)\end{array}$ & 242 & & \\
\hline Piped into the house & & $16(31.4)$ & $71(36.9)$ \\
\hline Bought from tankers & & $16(31.4)$ & $63(32.8)$ \\
\hline Bought from drums & & $19(37.2)$ & $57(29.7)$ \\
\hline $\begin{array}{l}\text { Use of flush toilet } \\
\text { facility; } n(\%)\end{array}$ & 237 & $0(0)$ & $2(1.0)$ \\
\hline Use of boiled water; n (\%) & 243 & $10(19.6)$ & $40(20.8)$ \\
\hline \multicolumn{4}{|l|}{ Antenatal characteristics } \\
\hline $\begin{array}{l}\text { Age at first pregnancy } \\
\text { (years) Mean(SD) }\end{array}$ & 243 & $18.8(2.2)$ & $18.9(3.6)$ \\
\hline $\begin{array}{l}\text { Child gestational age in } \\
\text { weeks Mean(SD) }\end{array}$ & 241 & $36.6(1.2)$ & $36.7(3.9)$ \\
\hline $\begin{array}{l}\text { Number of antenatal } \\
\text { visits during current } \\
\text { pregnancy; } \mathrm{n}(\%)\end{array}$ & 238 & & \\
\hline 0 & & $36(70.6)$ & $140(72.9)$ \\
\hline 1 & & $5(9.8)$ & $9(4.7)$ \\
\hline 2 & & $4(7.8)$ & $23(11.9)$ \\
\hline 3 and above & & $5(9.8)$ & $16(8.3)$ \\
\hline Clinical characteristics & & Mean (SD) & Mean (SD) \\
\hline Fever & 243 & $7.2(7.4)$ & $6.8(7.9)$ \\
\hline Cough $\sim$ & 243 & $10.2(9.4)$ & $8.5(7.3)$ \\
\hline Difficulty breathing & 243 & $10.6(10.9)$ & $8.2(7.7)$ \\
\hline Runny nose $\sim$ & 243 & $10.7(8.5)$ & $10.9(7.3)$ \\
\hline Sore throat $\sim$ & 243 & $10.0(9.1)$ & $9.1(8.1)$ \\
\hline
\end{tabular}

Table 1 Descriptive Analysis of the characteristics of pregnant women with low birth weight infants compared to those with normal birth weight infants (Continued)

\begin{tabular}{llll}
\hline Headache & 243 & $18.7(13.3)$ & $20.4(13.1)$ \\
Chills $\sim$ & 243 & $6.6(6.1)$ & $5.3(6.2)$ \\
Myalgias/Lethargy & 243 & $19.0(9.8)$ & $18.0(9.0)$ \\
Diarrhea & 243 & $3.3(4.3)$ & $4.6(6.8)$ \\
Vomiting & 243 & $6.2(9.0)$ & $6.2(8.9)$ \\
Total number of Respiratory & 243 & $102.9(49.7)$ & $96.1(41.3)$ \\
symptom episodes* $~$ & & & \\
Infant characteristics & & Mean (SD) & Mean (SD) \\
Weight of the infant(kg) & 243 & $2.1(0.2)$ & $3.0(0.4)$ \\
Height of the infant $(\mathrm{cm})$ & 243 & $45.6(2.5)$ & $49.5(3.2)$ \\
MUAC** of infant $(\mathrm{cm})$ & 241 & $8.4(0.9)$ & $9.8(0.8)$ \\
OFC*** of infant $(\mathrm{cm})$ & 242 & $31.7(1.3)$ & $34.2(1.4)$ \\
\hline
\end{tabular}

* Respiratory symptoms included eight symptoms (cough, difficulty breathing, runny nose, sore throat, headache, chills, and myalgia/lethargy)

$\sim$ Episodes per 100 weeks of pregnancy

**Mid upper arm circumference

***Occipitofrontal circumference

belonging to high SES. One explanation for this observation is that amongst women from low SES, there are other factors including poor maternal nutritional status, low education and inaccessibility to appropriate water sources that influence the weight of the newborn adversely. As a result, the effect of maternal respiratory illnesses on low birth weight is blunted and a trend of association was not shown in that subset of mothers with lower SES.

This study explores an association between newborn birth weights with the maternal respiratory morbidities during pregnancy in the community settings. Other studies have explored associations of vaginal infections [17] and periodontal infections [18] in pregnancy with delivering LBW infants. The strength of our study lies in the observational cohort design, where we actively followed pregnant women every week for presence of fever and respiratory symptoms in the previous seven days. Through this study design, we were able to demonstrate an appropriate temporal sequence between exposure of pregnant women with fever and respiratory illnesses and the outcome of LBW newborns. In our study sample, we found $21 \%$ of delivered newborns had LBW, which is comparable to the Pakistan Demographic and Health Survey data (26\% low birth weight infants) for the period 20062007 [19].

In univariate analysis, we observed an association between increased parity and a decreased risk of having a newborn with LBW. It is consistent with the finding that second and third newborns usually weigh more than the 
Table 2 Univariate Logistic Regression Analysis of the characteristics of pregnant women to identify factors associated with low birth weight of infants $(n=222)$

\begin{tabular}{|c|c|c|c|c|}
\hline \multicolumn{2}{|l|}{ Pregnant women characteristics } & \multirow{2}{*}{$\frac{\text { Crude OR }}{0.7}$} & \multirow{2}{*}{$\frac{(95 \% \mathrm{Cl})}{(0.50 .9)}$} & \multirow{2}{*}{$\frac{P \text {-value }}{0.032}$} \\
\hline Pregnant women age (years) & For every 5 year increase & & & \\
\hline Age at first pregnancy (years) & For every 5 year increase & 0.9 & $(0.61 .5)$ & 0.796 \\
\hline Gravidity (total number of pregnancies) & For every 1 unit increase & 0.8 & $(0.70 .9)$ & 0.031 \\
\hline Weight at first visit (kg) & For every $10 \mathrm{~kg}$ weight increase & 0.6 & $(0.50 .9)$ & 0.006 \\
\hline Height of pregnant women (cm) & For every $10 \mathrm{~cm}$ increase & 0.9 & $(0.7$ 1.3) & 0.739 \\
\hline \multirow[t]{3}{*}{ Pregnant women education } & No education & 1 & & 0.805 \\
\hline & Below high school equivalent & 0.8 & $(0.31 .8)$ & \\
\hline & High school equivalent and above & 0.9 & (0.3 2.4) & \\
\hline \multicolumn{5}{|l|}{ Household characteristics } \\
\hline No of people living in house hold & For every 1 unit increase & 1.0 & $(0.9$ 1.1) & 0.766 \\
\hline No of rooms in the household & For every 1 unit increase & 1.0 & $(0.81 .3)$ & 0.738 \\
\hline Total score of household assets & For every 200 unit increase & 0.7 & $\left(\begin{array}{l}0.4 \\
0.9\end{array}\right)$ & 0.073 \\
\hline \multirow[t]{3}{*}{ Source of drinking water } & Piped water & 1 & & 0.578 \\
\hline & Water bought from tankers & 1.1 & $(0.52 .4)$ & \\
\hline & Water bought from drums & 1.5 & $(0.73 .1)$ & \\
\hline \multirow[t]{2}{*}{ Use of boiled water } & Yes & 0.9 & $(0.42 .0)$ & 0.847 \\
\hline & No & 1.0 & - & \\
\hline \multicolumn{5}{|l|}{ Antenatal characteristics } \\
\hline Child gestational age in weeks & For every 1 week increase & 0.4 & $(0.20 .8)$ & 0.000 \\
\hline \multirow[t]{2}{*}{ First pregnancy } & No & 1 & & 0.798 \\
\hline & Yes & 0.9 & $(0.42 .1)$ & \\
\hline Number of antenatal visits during current pregnancy & For every 1 visit increase & 1.0 & $\left(\begin{array}{lll}0.8 & 1.3\end{array}\right)$ & 0.828 \\
\hline \multirow[t]{3}{*}{ Delivery location of last child } & No previous pregnancy & 1 & $(0.42 .6)$ & 0.815 \\
\hline & Maternity home & 1.0 & & \\
\hline & Home & 1.2 & $(0.52 .9)$ & \\
\hline \multicolumn{5}{|l|}{ Clinical characteristics } \\
\hline Maternal fever ${ }^{a}$ & For every 10 episode increase & 1.1 & $(0.7$ 1.6) & 0.698 \\
\hline Maternal diarrhea ${ }^{a}$ & For every 5 episode increase & 0.8 & $(0.61 .1)$ & 0.178 \\
\hline Maternal vomiting ${ }^{a}$ & For every 10 episode increase & 0.9 & $(0.7$ 1.4) & 0.969 \\
\hline Total number of Respiratory symptom episodes ${ }^{a}$ & For every 50 episodes increase & 1.2 & $(0.81 .8)$ & 0.313 \\
\hline
\end{tabular}

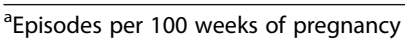

first newborn in a family [20]. Similar to other previously published studies, this study supports that low SES of the pregnant mother is associated with an increase in the risk of having a newborn with LBW [21].

There are several limitations of the current study which include small sample size, assessment of illness by report only and limited ability to identify severity of illness. Although we enrolled 400 pregnant women, a 100 more than the required sample size to account for the expected loss of follow-up in this long surveillance study, 39\% dropout was still higher than expected. Major reason for this dropout was migration of pregnant women to native places around the peri partum period. Another limitation is that the birth weight was recorded within 0-14 days of birth (mean age 4.9 days) due to the fact that in this community, access to the mother and the newborn baby can be difficult in the immediate post-partum period. The gestational age was measured by taking the date of the last menstrual period from the mothers instead of by ultrasound documentation due to logistic constraints. Finally, we could not assess some interactions for significance in the final multivariable model due to sparse data (that led to zero cell counts and hence numerically unstable logistic regression model). 
Table 3 Multivariable Logistic Regression Model ${ }^{a}$ to identify factors associated with infant low birth weight $(n=222)$

\begin{tabular}{|c|c|c|}
\hline Variables & Adj OR & $(95 \% \mathrm{Cl})$ \\
\hline \multicolumn{3}{|l|}{ Mother's weight at first visit } \\
\hline$<57.5 \mathrm{Kg}$ & 5.1 & (1.3 19.9) \\
\hline$\geq 57.5 \mathrm{Kg}$ & 1 & - \\
\hline Child gestational age (weeks) & $0.3^{b}$ & $(0.20 .7)$ \\
\hline \multicolumn{3}{|c|}{$\begin{array}{l}\text { Association between number of episodes of } \\
\text { respiratory illness } / 100 \text { weeks of pregnancy and SES }\end{array}$} \\
\hline High SES & $1.7^{d}$ & $(1.03 .1)$ \\
\hline \multicolumn{3}{|l|}{$\begin{array}{l}\text { number of episodes of respiratory illness / } \\
100 \text { weeks of pregnancy } \\
\text { Low SES }\end{array}$} \\
\hline $\begin{array}{l}\text { number of episodes of respiratory illness / } \\
100 \text { weeks of pregnancy }\end{array}$ & $0.9^{d}$ & $(0.53 .5)$ \\
\hline \multicolumn{3}{|c|}{$\begin{array}{l}\text { Interaction between number of fever episodes/ } \\
100 \text { weeks of pregnancy and Gravidity } \\
\text { number of fever episodes/100 weeks of pregnancy }\end{array}$} \\
\hline Gravidity $^{e}=2$ & & $(0.3,2.2)$ \\
\hline$\geq 11$ & 0.8 & - \\
\hline$<11$ & 1.0 & \\
\hline Gravidity $=3$ & & $(0.5,3.0)$ \\
\hline$\geq 11$ & 1.3 & - \\
\hline$<11$ & 1.0 & \\
\hline Gravidity $=5$ & & $(1.1,10.5)$ \\
\hline$\geq 11$ & 3.4 & - \\
\hline$<11$ & 1.0 & \\
\hline Gravidity $=7$ & & $(1.4,57.6)$ \\
\hline$\geq 11$ & 9.0 & - \\
\hline$<11$ & 1.0 & \\
\hline Gravidity $=9$ & & $(1.7,357.2)$ \\
\hline$\geq 11$ & 24.2 & - \\
\hline$<11$ & 1.0 & \\
\hline
\end{tabular}

adjusted for mother's age and number of episodes of diarrhea/100 weeks of pregnancy

-2 Log-Likelihood $=187.701$, Hosmer \& Lemeshow goodness of fit

test $p$-value $=0.566$

b. Odds Ratio (and 95\% Cl) corresponds to every one week increase in gestational age

c. SES (Socio-Economic Status). Total score of assets $<142$ is labeled as "low" and $\geq 142$ as "high" SES

d. Odds Ratio (and $95 \% \mathrm{Cl}$ ) corresponds to every 50 unit increase in number of episodes of respiratory illness $/ 100$ weeks of pregnancy

e. For values of "Gravidity" minimum $=1$, maximum $=11,25$ th percentile $=2$, 50th percentile $=3$, 75 th percentile $=5$

\section{Conclusion}

While overall respiratory illnesses during pregnancy did not impact LBW in our study, we found this trend in the sub-group of mothers belonging to the higher SES. Whether this is because in mothers belonging to lower SES, the effects of respiratory illnesses were overshadowed by other risk factors associated with poverty need to be further studied.

\section{Abbreviations}

ARI: Acute respiratory infections; Cl: Confidence interval; DSS: Demographic surveillance system; LBW: Low birth weight; OR: Odds ratio; PCA: Principal component analysis; SD: Standard deviation; SES: Socio-economic status.

\section{Acknowledgments}

We thank all the patients and their families for participating in this study. We acknowledge Samana Zaidi for making substantial contributions to the acquisition of data and supervision of the field staff.

Funding

This project was funded by a grant from the US DOD (HDTRA1-10-1-0082).

\section{Availability of data and materials}

The datasets used and analysed during the current study available from the corresponding author on reasonable request.

\section{Author's contributions}

AA substantially contributed in the design, conduct and write up of the study. UZ has made substantial contributions (1) to design, acquisition and analysis and interpretation of data; 2) have been involved in drafting the manuscript and revising it critically for important intellectual content. SM conducted the principal component analysis for respiratory symptoms, and made the major contribution for conducting multivariable logistic regression analysis, wrote the results and interpretations from these inferential models and critically reviewed the manuscript. GSZ has made substantial contributions in the analysis and write-ups of the manuscript. MK has made substantial contributions in the design and conduct of the study. WP has made substantial contributions in the design and planning of the study and critical review of the manuscript. ZB has made substantial contributions in the design and conduct of the study and critical review of the manuscript. AZ has made substantial contributions in the design and conduct of the study and critical review of the manuscript. MH has made substantial contributions in the design, planning and conduct of the study as well as critical review of the manuscript. All the listed authors have read and approved the final manuscript.

\section{Competing interests}

The authors declare that they have no competing interests.

\section{Consent for publication}

Not Applicable

\section{Ethics approval and consent to participate}

This study was conducted under approval by institutional review boards at the Aga Khan University, Karachi, Pakistan and University of Virginia, Charlottesville, Virginia, USA. Informed consent was obtained from the adult participants and by a parent's informed consent for newborns.

\section{Publisher's Note}

Springer Nature remains neutral with regard to jurisdictional claims in published maps and institutional affiliations.

\section{Author details}

'Department of Pediatrics and Child Health, The Aga Khan University, Karachi 74800 , Pakistan. ${ }^{2}$ Division of Infectious Diseases, University of Virginia School of Medicine Carter-Harrison Building, Room 1704, 345 Crispell Drive, Charlottesville, VA 22908, USA.

Received: 15 November 2016 Accepted: 11 March 2017 Published online: 11 April 2017

\section{References}

1. Garenne M, McCaa R. Maternal mortality for 181 countries, 1980-2008. Lancet. 2010;376(9750):1389.

2. World Health O. The World Health Report 2005. Make every mother and child count. Geneva: World Health Organization; 2005. p. 2005.

3. Larson L, Mehta N, Paglia MJ. 1 Pulmonary disease in pregnancy. de Swiet's Medical Disorders in Obstetric Practice. 5th Edition, MA. USA: WileyBlackwell; 2010. p. 1-47

4. Yamaquchi K, Hisano M, Isojima S, Irie S, Arata N, Watanabe N, Kubo T, Kato T, Murashima A. Relationship of Th1/Th2 cell balance with the immune 
response to influenza vaccine during pregnancy. J Med Virol. 2009;81(11): 1923-8.

5. Dodds L, McNeil SA, Fell DB, Allen VM, Coombs A, Scott J, MacDonald N. Impact of influenza exposure on rates of hospital admissions and physician visits because of respiratory illness among pregnant women. CMAJ. 2007; 176(4):463-8.

6. Hisano M, Yamaguchi K. Usefulness of influenza vaccination during pregnancy to mothers and young infants. Expert Rev Vaccines. 2012;11(8):903-5.

7. Rasmussen SA, Jamieson DJ, MacFarlane K, Cragan JD, Williams J, Henderson Z. Pandemic influenza and pregnant women: summary of a meeting of experts. Am J Public Health. 2009;99(S2):248-54.

8. Siston AM, Rasmussen SA, Honein MA, Fry AM, Seib K, Callaghan WM, Louie J, Doyle TJ, Crockett M, Lynfield R. Pandemic 2009 influenza A (H1N1) virus illness among pregnant women in the United States. JAMA. 2010;303(15):1517-25.

9. Steinhoff MC, Omer SB, Roy E, El Arifeen S, Raqib R, Dodd C, Breiman RF, Zaman K. Neonatal outcomes after influenza immunization during pregnancy: a randomized controlled trial. CMAJ. 2012;184(6):645-53.

10. Benowitz I, Esposito DB, Gracey KD, Shapiro ED, Vuzquez M. Influenza vaccine given to pregnant women reduces hospitalization due to influenza in their infants. Clin Infect Dis. 2010;51(12):1355-61.

11. Zaman K, Roy E, Arifeen SE, Rahman M, Raqib R, Wilson E, Omer SB, Shahid NS, Breiman RF, Steinhoff MC. Effectiveness of maternal influenza immunization in mothers and infants. N Engl J Med. 2008;359(15):1555-64.

12. A study done by Centers for Disease Control and Prevention (CDC). Maternal, C.D.C and infant outcomes among severely ill pregnant and postpartum women with 2009 pandemic influenza A (H1N1)-United States, April 2009August 2010. MMWR Morb Mortal Wkly Rep. 2011;60(35):1193-196.

13. Martin A, Cox S, Jamieson DJ, Whiteman MK, Kulkarni A, Tepper NK. Respiratory IIIness Hospitalizations Among Pregnant Women During Influenza Season, 1998-2008. Matern Child Health J. 2013;17(7):1325-31.

14. SPSS 15.0 for Windows. Chicago: SPSS Inc (Release 15.0.0 .2006).

15. Johnson RA, Wichern DW. Applied multivariate statistical analysis, vol. 5 . Upper Saddle River: Prentice hall; 2002.

16. Hosmer DW, Lemeshow S. Applied Logistic Regression. 2000. 330-9

17. Donders GG, Desmyter J, De Wet DH, Van Assche FA. The association of gonorrhoea and syphilis with premature birth and low birthweight. Genitourin Med. 1993:69(2):98-101.

18. Dasanayake AP. Poor periodontal health of the pregnant woman as a risk factor for low birth weight. Ann Periodontol. 1998;3(1):206-12

19. Zakar R, Zakar MZ, Aqil N, Nasrullah M. Paternal factors associated with neonatal deaths and births with low weight: evidence from Pakistan demographic and health survey 2006-2007. Maternal and child health journal. 2015;19(7):1634-42.

20. Roth J, Hendrickson J, Schilling M, Stowell DW. The risk of teen mothers having low birth weight babies: implications of recent medical research for school health personnel. J Sch Health. 1998;68(7):271-5.

21. Valero De Bernabé J, Soriano T, Albaladejo R, Juarranz M, Calle ME, Martínez D, Domínguez-Rojas V. Risk factors for low birth weight: a review. Eur J Obstet Gynecol Reprod Biol. 2004;116(1):3-15.

\section{Submit your next manuscript to BioMed Central and we will help you at every step:}

- We accept pre-submission inquiries

- Our selector tool helps you to find the most relevant journal

- We provide round the clock customer support

- Convenient online submission

- Thorough peer review

- Inclusion in PubMed and all major indexing services

- Maximum visibility for your research

Submit your manuscript at www.biomedcentral.com/submit

CBiomed Central 